\title{
Никитин В.В. \\ Факторы, влияющие на выбор технологии строительства быстровозводимых модульных зданий в условиях ЧС
}

Национальный исследовательский Московский государственный строительный университет (НИУ МГСУ)

(Россия, Москва)

doi: 10.18411/trnio-11-2021-68

\section{Аннотация}

Эффективность применения быстровозводимых модульных зданий в условии ЧС зависит от влияния множества факторов, положительных и отрицательных. Выявление данных факторов позволит достичь граммотного планирования и проектирования застройки территорий, для населения, пострадавшего в ЧС.

В связи с этим целью статьи является рассмотрение факторов, влияющих на выбор технологии строительства быстровозводимых модульных зданий в условиях чрезвычайных ситуаций в конкретных географических и климатических условиях.

Ключевые слова: чрезвычайные ситуации, быстровозводимые модульные здания, монтаж быстровозводимых модульных зданий.

\section{Abstract}

The effectiveness of the use of prefabricated modular buildings in an emergency depends on the influence of positive factors. Identification of factors to achieve the achievement of grammatical planning and design of the development of territories for the population affected by emergencies.

In this regard, the direction of consideration of the factors influencing the choice of technology for constructing prefabricated modular buildings in emergencies in geographic and climatic conditions.

Keywords: emergencies, prefabricated modular buildings, assembly of prefabricated modular buildings.

Чрезвычайные ситуации сопряжены с материальным ущербом для населения и зачастую связанны с потерей жилья. Федеральным законодательством предусмотрено приобретение или строительство жилья взамен утраченного. Опыт реализации показывает, что данные меры требуют значительных временных затрат. Однако в условиях возникновения чрезвычайных ситуаций (ЧС) перед государством стоит вопрос в скорейшем расселении населения эвакуированного с пострадавших территорий.

Для быстрого обеспечения населения, пострадавшего во время чрезвычайных ситуаций рационально использовать быстровозводимые модульные здания. Основные элементы быстровозводимых модульных зданий изготавливаются в заводских условиях и доставляются на строительную площадку автомобильным, железнодорожным или водным транспортом. Строительство быстровозводимого дома с отделкой и инженерными коммуникациями занимает всего 3-6 месяцев, а также неоспоримым преимуществом является всесезонность производства работ по их возведению.

Быстровозводимые здания можно классифицировать по конструкции элементов несущих и ограждающих конструкций на:

— п панельные (SIP, MHM, CLT, НБКС «МОДОС». и т.д.);

— стоечно-панельные («Модуль», «Сокол», ЛСТК и т.д.);

- рамно-панельные («Сокол»;

- из блок-контейнеров («Универсал»., «Энергетик», «Геолог» и т.д.)

При существующем многообразии быстровозводимых модульных зданий встает вопрос о оптимальности применении той или иной технологии, с этой целью необходимо провести оценку факторов, влияющих на выбор технологии.

Во время проведения исследования была использована диаграмма Исикавы для выявления основных факторов и поиска наиболее существенных причинно-следственных 
взаимосвязей. В результате были получены такие важные показатели, влияющие на выбор технологии, как: материально-технические ресурсы в зоне производства работ, сам процесс производство работ по определенной технологии, логистика, экономические показатели, объемно-планировочные решения, трудовые ресурсы, документация.

Также диаграмма Исикавы помогла найти и получить взаимосвязь дополнительных факторов:

1. Материально-технические ресурсы:

- возможность использования местных материальных ресурсов;

- возможность использования местных технических ресурсов.

2. Производство работ:

- использование средств механизации с учетом местных условий;

- возможность применения рациональных методов строительства;

- скорость монтажа/демонтажа.

3. Логистика:

- возможность транспортировки до места ЧС.

4. Экономические показатели:

- стоимость домокомплекта;

- стоимость доставки домокомплекта;

- стоимость работ по сборке домокомплекта.

5. Объемно-планировочные решения:

— планировочная структура помещений;

- этажность;

- строительный объем.

6. Трудовые ресурсы:

- возможность привлечения местных трудовых ресурсов;

- уровень квалификации персонала.

7. Документация:

- унификация узлов и деталей;

- технологичность документации.

Наглядно факторы, влияющие на выбор технологии строительства БВМЗ, представлены на рис.1:

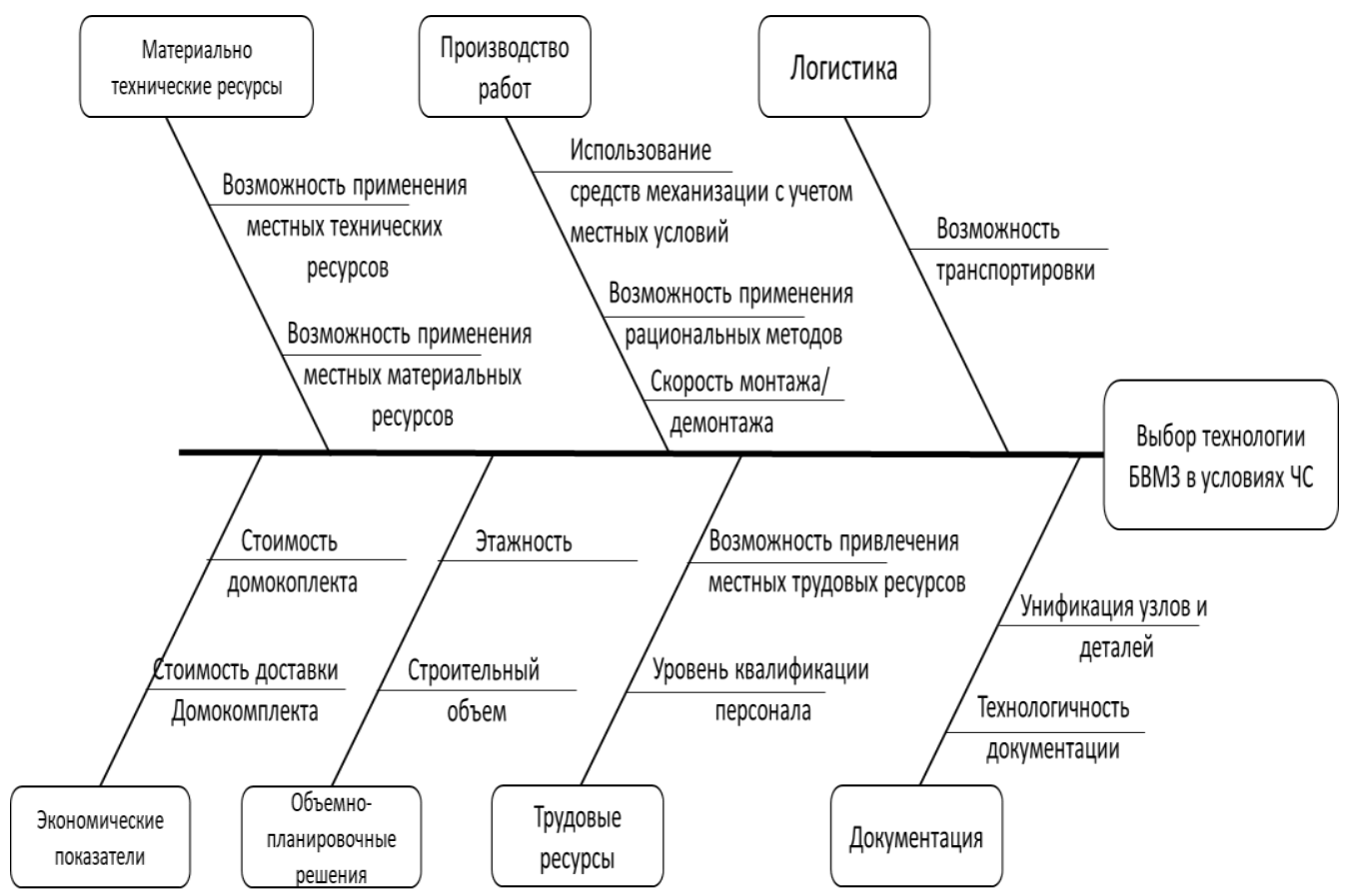

Рисунок 1. Диаграмма Исикавы. Факторы, влияющие на выбор технологии БВМЗ 
Для оценки влияния каждого фактора на выбор технологии строительства быстровозводимых модульных зданий, будет использован метод экспертных оценок, получены показатели по эффективности применения определенной технологии зависимости от территории размещения объектов строительства и выявлена технология, для каждой территории.

$$
* * *
$$

1. Асаул А. Н., Казаков Ю. Н., Князь И. П., Ерофеев П. Ю. Теория и практика использования быстровозводимых зданий в обычных условиях и чрезвычайных ситуациях в России и за рубежом / под ред. Ю. Н. Казакова. СПб.: Гуманистика, 2004. 472 с

2. Исследование факторов совершенствования технологий высокоскоростного модульного строительства / Сычев С.А. - Санкт-Петербург: Вестник ЮУрГУ. Серия «Строительство и архитектура». 2016. Т. 16, № 1. С. $35-40$.

3. S. Russo Ermolli. The environmental benefits of the Off-Site Manufacturing. SB07 Lisbon - Sustainable Construction, Materials and Practices: Challenge of the Industry for the New Millenium, (), 12 Sep 2007 - 14 Sep 2007. Rotterdam (Netherlands)

\section{Анализ открытого и бестраншейного способа восстановления трубопровода}

Уральский федеральный университет им. первого Президента России Б.Н.Ельцина (Россия, Екатеринбург)

doi: 10.18411/trnio-11-2021-69

\section{Аннотация}

В статье рассматривается сравнительный анализ способов восстановления трубопровода. Преимущества и недостатки открытого и бестраншейного способа восстановления по ряду критериев оценки. Актуальность внедрения новых технологий при восстановлении наружных сетей.

Ключевые слова: бестраншейный метод, открытый способ, трубопровод, канализация, наружные сети, подземные коммуникации.

\section{Abstract}

The article deals with a comparative analysis of the methods of pipeline restoration. Advantages and disadvantages of open and trenchless recovery method according to a number of evaluation criteria. The relevance of the introduction of new technologies in the restoration of external networks.

Keywords: trenchless method, open method, pipeline, sewerage, external networks, underground communications.

Одной из главных задач коммунальных служб в современных городах является предотвращение старения и преждевременного выхода из строя водопроводных сетей. Особенно это актуально для России, т.к старение подземных трубопроводов и оборудования различного назначения достигают критического значения. Более 50\%подземных коммуникаций уже пережили свой нормативный срок службы. Если не принимать оперативных мер повышения эффективности, работоспособности и реновации подземных трубопроводов, то это усугубит ситуацию многочисленными негативными последствиями для населения и окружающей природной среды.

В настоящее время существует два способа замены канализационных труб: открытым способом и бестраншейным.

Открытый способ: Прокладывание канализации в траншее сопряжено с такими трудностями, как необходимость долгого согласования проекта с инстанциями, чьи интересы будут затронуты при проведении земляных работ. Перекрытие движения по магистралям и пешеходным дорогам, что в результате приведет к нарушению расписания движения 